Knox, R. \& Collard, P. (1952). J. gen. Microbiol. 6, 369-373.

\title{
The Effect of Temperature on the Sensitivity of Bacillus cereus to Penicillin
}

\author{
BY R. KNOX AND P. COLLARD \\ Department of Bacteriology, Guy's Hospital Medical School, London
}

\begin{abstract}
SUMMARY: A strain of Bacillus cereus known to produce penicillinase adaptively was tested for penicillin sensitivity at different temperatures. With small inocula, the organisms grew freely at $37^{\circ}$ in concentrations of penicillin up to a hundred times greater than those which completely suppressed their growth at $\mathbf{4 2}^{\circ}$. This difference in apparent sensitivity almost disappeared when the inoculum was very heavy or consisted of cells which had been allowed to adapt by previous growth in the presence of penicillin.
\end{abstract}

The penicillinase of Bacillus cereus, NRRL 569 was shown by Pollock (1950) to be formed adaptively. He also found that 'no significant amount of enzyme was formed at $18^{\circ}$, and about four times as much at $35^{\circ}$ as at $30^{\circ}$. In earlier work on the adaptive formation of bacterial tetrathionase (Knox \& Pollock, 1944), it had been found that the process of adaptation was much more sensitive to heat than was the fully formed enzyme (Pollock, 1945), while the known growth-promoting effect of tetrathionate in semi-anaerobic conditions (Knox, 1945) was suppressed at temperatures such as $42^{\circ}$ at which adaptive formation of the enzyme was also suppressed (Knox, 1950).

In view of these facts, it was decided to study the effect of temperature on the growth of a known penicillinase-producing organism in the presence of penicillin.

\section{METHODS}

The organism used was $B$. cereus, NRRL 569 obtained from Dr Pollock. Cultures were maintained by serial subculture at weekly intervals on slopes of nutrient agar kept at room temperature. From these, 6 or $18 \mathrm{hr}$. broth cultures were used to inoculate experimental tubes or flasks. In most experiments 6 in. $\times \frac{5}{8}$ in. tubes were incubated in water-baths having a range about the stated temperature of $\pm \mathbf{0 \cdot 5 ^ { \circ }}$. In a few experiments $250 \mathrm{ml}$. conical flasks were used to obtain better aeration by increasing the surface/volume ratio. Growth after $18 \mathrm{hr}$. incubation was measured roughly by visible opacity (recorded as + or 0 ), or, where quantitative comparisons were wanted, on the density scale (at $\lambda 400$ ) of a Unicam spectrophotometer; rectangular cells $1 \mathrm{~cm}$. in depth were used, with a sample of uninoculated medium as a 'blank'. It was found that with an $18 \mathrm{hr}$. culture in broth a density reading of 0.2 was given by $285 \times 10^{6}$ cells $/ \mathrm{ml}$. (dry weight $0 \cdot 27 \mathrm{mg} . / \mathrm{ml}$.).

\section{RESULTS}

The effect of temperature on growth in nutrient broth

In nutrient broth in the absence of penicillin it was found that the organisms grew well over the range $22-45^{\circ}$ but failed to grow at $48^{\circ}$. At $45^{\circ}$ quantitative measurements of growth could not be made because of pellicle formation. 
Table 1 shows the results of inoculating $0.02 \mathrm{ml}$. of an $18 \mathrm{hr}$. broth culture into $10 \mathrm{ml}$. of nutrient broth incubated for $18 \mathrm{hr}$. at different temperatures.

It is clear that the organisms grew adequately up to temperatures as high as $42^{\circ}$, though, as would be expected, growth in flasks was much heavier than in tubes. In another experiment good growth was also obtained up to $42^{\circ}$ in tubes of broth inoculated with $0.02 \mathrm{ml}$. of a 1/1000 dilution of an $18 \mathrm{hr}$. broth culture.

Table 1. Effect of temperature on growth of $\mathrm{B}$. cereus in broth

\begin{tabular}{|c|c|c|c|c|}
\hline & & & & \\
\hline & $22^{\circ}$ & $37^{\circ}$ & $42^{\circ}$ & $45^{\circ}$ \\
\hline & & (spect & eter res & \\
\hline 6 in. $\times \frac{5}{8}$ in. tubes & $0 \cdot 165$ & $0 \cdot 125$ & $0 \cdot 115$ & $\mathbf{P}+$ \\
\hline $250 \mathrm{ml}$. flasks & 0.540 & $1 \cdot 000$ & $0 \cdot 620$ & $\mathbf{P}+$ \\
\hline
\end{tabular}

$\mathrm{P}+=$ pellicle growth. Inoculum: $0.02 \mathrm{ml}$. $18 \mathrm{hr}$. broth culture in $10 \mathrm{ml}$. medium. Incubation: $18 \mathrm{hr}$.

Table 2. Effect of temperature on growth of $\mathbf{B}$. cereus in penicillin broth

\begin{tabular}{|c|c|c|c|c|}
\hline & & Tem & & \\
\hline & $22^{\circ}$ & $37^{\circ}$ & $42^{\circ}$ & $45^{\circ}$ \\
\hline & & spectro & ter reac & \\
\hline //1 inoculum & $0 \cdot 085$ & $0 \cdot 195$ & $0 \cdot 18$ & 0 \\
\hline $1 / 1000$ inoculum & 0.015 & $0 \cdot 2$ & 0 & 0 \\
\hline
\end{tabular}

Inoculum: $0.02 \mathrm{ml} .18 \mathrm{hr}$. broth culture. Incubation: $18 \mathrm{hr}$. in $6 \mathrm{in.} \times \frac{5}{8}$ in. tubes.

The effect of temperature and inoculum size on growth in penicillin broth

In broth containing 10 units of penicillin $/ \mathrm{ml}$. good growth was obtained up to $42^{\circ}$ when a large inoculum was used, but only up to $37^{\circ}$ when the inoculum was a thousand times smaller (Table 2).

The effect of different inocula upon the penicillin sensitivity at 37 and $42^{\circ}$ was then further investigated. $0.02 \mathrm{ml}$. of $1 / 1,1 / 10,1 / 100$ and $1 / 1000$ dilutions of a $6 \mathrm{hr}$. broth culture of $B$. cereus were inoculated into tubes of broth containing 0, 1, 10, 100 and 1000 units of penicillin $/ \mathrm{ml}$. (Table 3A). It is evident that inoculum size was much more critical at $42^{\circ}$ than at $37^{\circ}$.

The effect of previous adaptation on growth of different inocula in penicillin broth at $37^{\circ}$ and $42^{\circ}$

Pollock (1950) showed that maximal adaptive production of penicillinase demanded conditions of full aeration. In the experiment shown in Table 3, three sets of inocula were prepared from cultures of $\boldsymbol{B}$. cereus grown in broth for $6 \mathrm{hr}$. at $37^{\circ}-\mathrm{A}$ in a $250 \mathrm{ml}$. conical flask, $\mathrm{B}$ in a $6 \mathrm{in} . \times \frac{5}{8} \mathrm{in}$. tube containing 1 unit of penicillin $/ \mathrm{ml}$. broth and $\mathrm{C}$ in a $250 \mathrm{ml}$. conical flask containing 1 unit 
of penicillin/ml. broth. Each inoculum was standardized to the same opacity and $0.02 \mathrm{ml}$. of different dilutions inoculated into tubes of broth as shown. After $18 \mathrm{hr}$. incubation the following results were obtained: (1) the level of penicillin in which the organism grew was in all cases a function of inoculum size; (2) at $37^{\circ}$ there was no difference between the levels tolerated by equal inocula of the three types of cell; (3) at $42^{\circ}$ the adapted cells were able to grow in from 10 to 100 times greater concentrations of penicillin than the unadapted cells; (4) with the smaller inocula the cells adapted in the flask grew in even higher concentrations than those adapted in the tube.

Table 3. Effect of inoculum size and previous adaptation on growth in penicillin broth at 37 and $42^{\circ}$

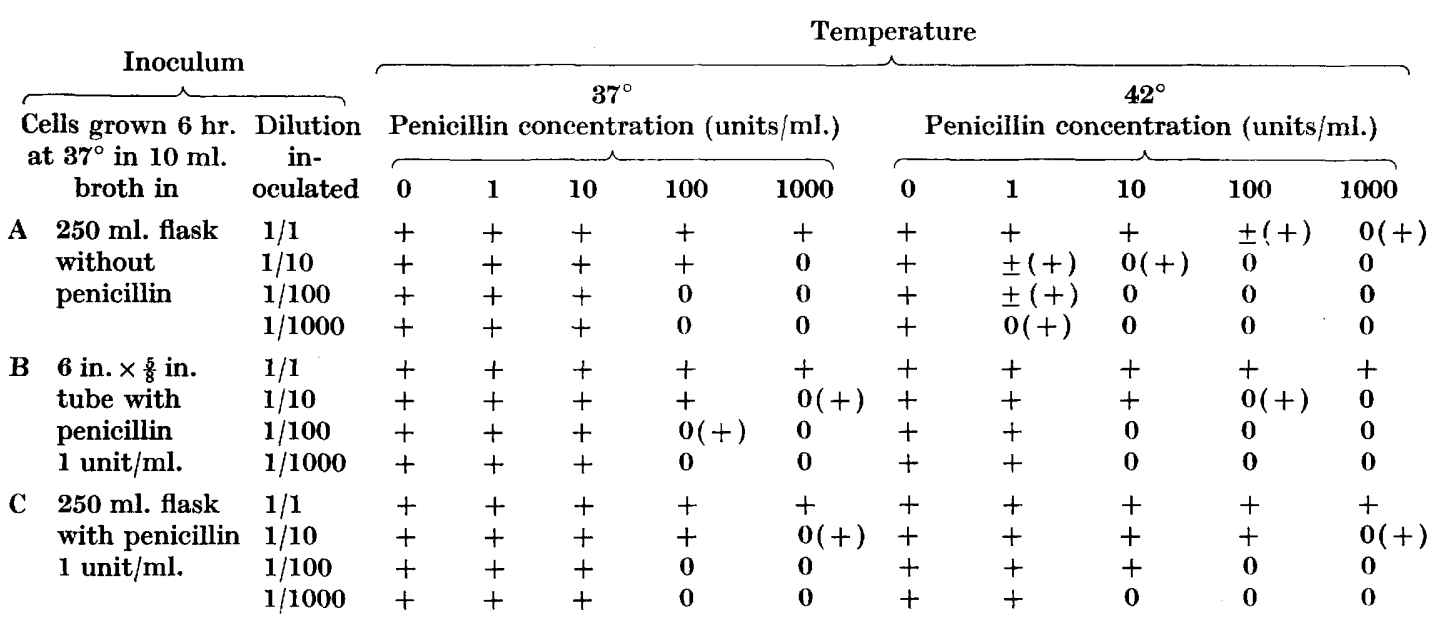

$+=$ good growth $\pm=$ faint growth; $0=$ no growth. All tubes were examined after incubating for $18 \mathrm{hr}$. and then for a further $72 \mathrm{hr}$. Brackets indicate those tubes which showed a change, e.g. $0(+)=$ no growth at $18 \mathrm{hr}$., good growth after a further $72 \mathrm{hr}$.

It should be noted that when the tubes were incubated for a further $\mathbf{7 2} \mathrm{hr}$., growth was found to have occurred in many of the cultures which had previously shown no growth, though others showed no growth after still further incubation, even in the presence of added penicillinase (Glaxo Laboratories, Greenford).

\section{DISCUSSION}

It seems that the apparent tube sensitivity of an organism is the resultant of a number of factors of which inoculum size and temperature are perhaps the most obvious. The effect of inoculum size upon the apparent sensitivity of penicillinase-producing organisms has been known for some years and has been used by Luria (1946) as the basis of a test for differentiating such organisms from other penicillin-resistant strains. The possible effect of temperature has not been so widely appreciated.

The most reasonable explanation of our findings appears to be as follows:

All cells of B. cereus 569 possess a basal quantity of penicillinase which can 
hydrolyse penicillin at 37 and $42^{\circ}$. The adaptive production of penicillinase can take place at $37^{\circ}$ but not at $42^{\circ}$. Growth cannot take place at penicillin concentrations above a certain level, approximately 1-2 units $/ \mathrm{ml}$. The fate of cells inoculated into penicillin containing media depends partly on the initial penicillin level and partly on the available penicillinase, which is itself determined by the size of the inoculum and the possibility of adaptation. There will therefore be a longer or shorter lag period during which penicillin is being destroyed but no growth is possible until this falls below the critical level. If sufficient cells survive this period, then growth will occur on prolonged incubation; on the other hand, the cells may suffer irreversible damage and die.

The experiments here described and the results obtained previously with tetrathionase provide two clear examples of the importance of adaptive mechanisms in bacterial growth. Both tetrathionase and penicillinase can be formed by a process of enzymic adaptation in conditions which exclude natural selection. Both adaptive processes are more sensitive to heat than the process of growth in the organisms investigated. In both cases it can be shown that if conditions are suitably chosen adaptation is a necessary condition for growth, and when penicillin is the substrate, it may even be a necessary condition for survival, since sensitive cells will be destroyed by penicillin if they cannot produce enough penicillinase to neutralize it first.

Adaptive mechanisms of this kind may be of vital importance for bacterial growth not only in the laboratory, but also in the animal body. For example, one way in which pyrexia could benefit the host is by suppressing adaptive mechanisms essential for survival and multiplication of the parasite. If this were so, reduction of body temperature by the use of antipyretic drugs could even swing the balance in favour of the parasite. Pasteur and his colleagues observed in 1878 (Pasteur, Joubert \& Chamberland, 1878) that fowls naturally immune to anthrax could be infected if the body temperature were artificially reduced. Pasteur's conclusion that the high body temperature $\left(42^{\circ}\right)$ of the fowl suppressed the growth of $\boldsymbol{B}$. anthracis was criticized when it was found that the organism grew well in the laboratory at $42-43^{\circ}$. But this criticism would lose its force if the virulence of $\boldsymbol{B}$. anthracis were found to depend on a thermolabile adaptive mechanism of the kind we have here described.

Artificially induced pyrexia, local or general, has been used in the treatment of a number of infections and some benefit might be expected from combining it with the use of antibiotics. This could occur in two ways: (1) as suggested by Marks (1951), in a recent paper on the effect of temperature on the sensitivity of tubercle bacilli to antibacterial agents, by suppressing the growth of all organisms except a few rare variants resistant to both the antibiotic and the higher temperature; (2) by the suppression of adaptive mechanisms in the parasite as, for example, in mixed infections complicated by penicillinaseproducing organisms.

We should like to thank Dr M. R. Pollock for the strain of $B$. cereus and Mr R. Woodroffe for technical assistance. 


\section{REFERENCES}

KNox, R. (1945). The effect of tetrathionate on bacterial growth. Brit. J. exp. Path. 26, 146.

KNox, R. (1950). Tetrathionase: The differential effect of temperature on growth and adaptation. $J$. gen. Microbiol. 4, 388.

Knox, R. \& Pollock, M. R. (1944). Bacterial tetrathionase: adaptation without demonstrable cell growth. Biochem. J. 38, 299.

LURIA, S. E. (1946). A test for penicillin sensitivity and resistance in staphylococcus. Proc. Soc. exp. Biol., N.Y. 61, 46.

Marks, J. (1951). Effects of hyperthermia and antibacterial agents on tubercle bacilli. Brit. med. J. ii, 1318.

Pasteur, L., Joubert, J. \& Chamberland, C. (1878). La théorie des germes et ses applications à la médecine et à la chirurgie. Bull. Acad. Méd., Paris, 2nd ser., $7,432$.

Pollock, M. R. (1945). The influence of temperature on the adaptation of 'tetrathionase' in washed suspensions of Bact. paratyphosum B. Brit. J. exp. Path. 26, 410 .

Pollock, M. R. (1950). Penicillinase adaptation in B. cereus: Adaptive enzyme formation in the absence of free substrate. Brit. J. exp. Path. 31, 739.

(Received 8 December 1951) 